\title{
Influenza in long-term Dutch travelers in the tropics: symptoms and infections
}

\author{
Jane Whelan', Guus F. Rimmelzwaan ${ }^{3}$, Anneke van den Hoek,2, Sanne-Meike Belderok ${ }^{1,2}$ \\ and Gerard J. B. Sonder ${ }^{1,2,4^{*}}$
}

\begin{abstract}
Background: Influenza is a common infection among travelers, and attack rates are well documented in short-term travelers and holiday makers. Little data exists on long-term, non-expatriate travelers.

Methods: This was a prospective mono-centre study of immunocompetent, Dutch travelers aged $\geq 18$ to 64 years. It was conducted at the Public Health Service travel clinic in Amsterdam from December 2008 to September 2011, and included all travelers intending to travel to a tropical or sub-tropical country.

Results: Among 602 Dutch long-term travelers to tropical regions, $82 \%$ had protective influenza antibody titres pre-travel. The influenza attack rate of serologically confirmed infection during travel was $15 \%$, and of symptomatic infection was $6.3 \%$ (fever alone) and $2 \%$ (ILI), respectively.

Conclusions: The attack rate in this study is similar to seasonal rates of infection in the general population. Influenza vaccination pre-travel is therefore most important for people at risk of medical complications due to influenza.
\end{abstract}

Keywords: Influenza, Seroconversion, Attack rate, Travelers

\section{Background}

Influenza is the most frequently reported vaccinepreventable disease affecting visitors to (sub) tropical countries [1]. In 2009, an increase in the proportion of travel-related respiratory disease in Europe, mostly attributable to pandemic $\mathrm{A}(\mathrm{H} 1 \mathrm{~N} 1)$ influenza, was recorded [2]. The impact of influenza virus infection on travelers in terms of morbidity, healthcare accessed and hospitalization, is well documented [3] in short-term holiday makers, business travelers, and other traveler groups (Hadj pilgrims [4], cruise-ship passengers [5]). Travelers are also an acknowledged risk for onward transmission while in transit and at home [6]. Western adults are traveling in unprecedented numbers to emerging economies (often tropical and subtropical regions), for prolonged periods for 'gap years', to work, study, and tour. In this study of Dutch long-term travelers (3 to 12 months) to (sub) tropical regions, we prospectively document the attack rate (AR) of influenza infection and

\footnotetext{
* Correspondence: gsonder@ggd.amsterdam.n

'Department of Infectious Diseases, Public Health Service Amsterdam, Nieuwe Achtergracht 100, 1018WT Amsterdam, The Netherlands

${ }^{2}$ Academic Medical Centre, Amsterdam, The Netherlands

Full list of author information is available at the end of the article
}

the incidence of influenza like illness (ILI) while traveling, and identify risk factors associated with symptomatic and asymptomatic infection from 2009 to 2011.

\section{Methods}

A prospective mono-centre study of immunocompetent, Dutch travelers aged $\geq 18$ to 64 years was conducted at the Public Health Service travel clinic in Amsterdam from December 2008 to September 2011. All clients planning to travel to any (sub) tropical country in Africa, Central America, the Caribbean, South America or Asia for $\geq 12$ and $\leq 52$ weeks were invited to participate. Pre-travel, clients were interviewed by a nurse or physician and asked about travel purpose (work/study or tourism), travel duration, planned destination(s), and demographic details. No influenza vaccination history was established, but in the Netherlands, influenza vaccination is not recommended for travelers or healthy, young adults. At the time of the study, vaccination was only recommended for people $\geq$ 65 years and people with certain chronic diseases. Participants were given a digital thermometer (Huikeshoven Medical, Tiel, The Netherlands) and asked to take their temperature if they felt feverish while traveling. They kept 
a structured, weekly travel diary, recording their itinerary, symptoms experienced including respiratory, gastrointestinal and other systemic complaints and physician visits while ill. Diaries were completed on paper or digitally. Travelers received a weekly email reminder and were seen 2 to 6 weeks after return. Blood samples were taken before and after travel and paired samples were tested simultaneously post-travel for antibodies against influenza viruses using the hemagglutination-inhibition (HI) assay $[7,8]$. Vaccine strains used represented the epidemic strains circulating worldwide during the study period: A(H1N1pdm09), A(H3N2brisbane), A(H3N2perth), $\mathrm{A}(\mathrm{H} 1 \mathrm{~N} 1$ brisbane), B/Florida and B/Brisbane [9]. Influenza infection was defined as a $\geq 4$-fold rise in antibody titre post-travel from a pre-travel titre of $\geq 10$, or if pretravel titer was $<10$ titer, a post-travel titer of $\geq 40$. Fever was defined as thermometer-confirmed body temperature $>38.0{ }^{\circ} \mathrm{C}$ and influenza like illness (ILI) was defined as fever and cough or sore throat in the absence of other diagnoses. Primary regions visited while travelling were categorized into Influenza Transmission Zones [10] and then into 4 regions: South East Asia, Africa, Central and Latin America and "Asia (Other)" (Fig. 1).

Differences in the proportion of confirmed influenza infections by sex, age-group, primary influenza transmission zone visited, fever $>38.0{ }^{\circ} \mathrm{C}$ and ILI were tested using Pearson's chi-squared for each influenza strain. Positive predictive value (PPV) for seroconversion was the proportion of symptomatic cases seroconverting for infection. The association between infection and ILI was tested using logistic regression and odds ratios with $95 \%$ confidence intervals. Incidence of fever and ILI while travelling was estimated as 1st episodes of fever or ILI per 100 personweeks of travel with Poisson distributed $95 \%$ confidence intervals (STATA version 13).

\section{Results}

\section{Study population}

Overall, 602 respondents were included. The median age was 25 years (IQR:23-30), and 64 \% $(n=389)$ were female; median travel duration was 20 weeks (IQR:16-25 weeks). Travelers' primary destinations (influenza transmission zone) are listed in Table 1 . Travel periods were: 228 (38 \%) travelled in 2009 (earliest departure: 9 December 2008), 309 (51 \%) through 2010, 255 (42\%) through 2011 and 47 (8 \%) through 2012 (latest return 01 September 2012). Pre-travel, $82 \%(n=496)$ had protective influenza antibody titres: 214 (36 \%) for A(H1N1pdm09), 264 (44 \%) for A(H3N2brisbane), 283 (47 \%) for $\mathrm{A}(\mathrm{H} 3 \mathrm{~N} 2$ perth), 202 (34 \%) for $\mathrm{A}(\mathrm{H} 1 \mathrm{~N} 1$ brisbane), 208 (35\%) for B/Florida and 68 (11 \%) for B/

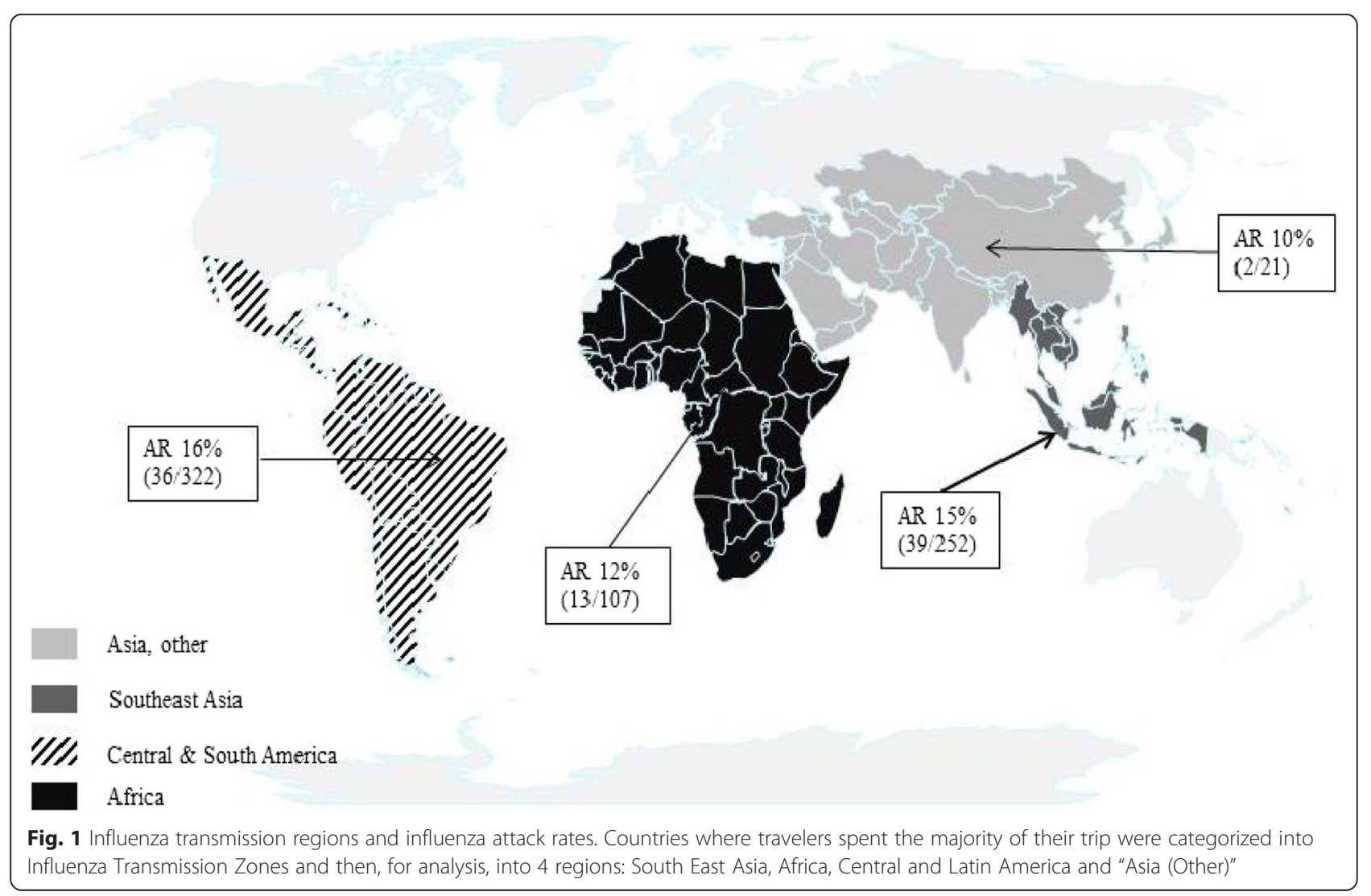


Table 1 Cross-tabulations of seroconversion for influenza viruses circulating worldwide during the study period for $n=602$ long-term Dutch travelers, 2009 to 2012

\begin{tabular}{|c|c|c|c|c|c|c|c|c|c|c|c|c|c|c|c|c|c|c|c|c|c|c|}
\hline \multirow[t]{2}{*}{ Variables } & \multirow{2}{*}{$\begin{array}{l}\text { Total } \\
\text { respondents } \\
\mathrm{N}\end{array}$} & \multicolumn{3}{|c|}{$\begin{array}{l}\text { Seroconversion for } \\
\text { any virus }^{\mathrm{a}}\end{array}$} & \multicolumn{3}{|c|}{$\begin{array}{l}\text { A/California/007/09 } \\
\text { H1N1pdm [H1 pdm09] }\end{array}$} & \multicolumn{3}{|c|}{$\begin{array}{l}\text { A/Brisbane/59/07 } \\
\text { [H1N1] }\end{array}$} & \multicolumn{3}{|c|}{$\begin{array}{l}\text { A/Brisbane/10/07 } \\
\text { [H3N2] }\end{array}$} & \multicolumn{3}{|c|}{$\begin{array}{l}\text { A/Perth/16/09 } \\
\text { [H3N2] }\end{array}$} & \multicolumn{3}{|c|}{ B/Florida/4/06 } & \multicolumn{3}{|c|}{ B/Brisbane/60/08 } \\
\hline & & $n$ & $\mathrm{n} / \mathrm{N} \%$ & $p$ value & $n$ & $\mathrm{n} / \mathrm{N} \%$ & $p$ value & $n$ & $\mathrm{n} / \mathrm{N} \%$ & $p$ value & $n$ & $\mathrm{n} / \mathrm{N} \%$ & $p$ value & $n$ & $\mathrm{n} / \mathrm{N} \%$ & $p$ value & $n$ & $n / N \%$ & $p$ value & $n$ & $\mathrm{n} / \mathrm{N} \%$ & $p$ value \\
\hline Total & 602 & 90 & 15 & N/A & 43 & 7 & N/A & 16 & 3 & N/A & 26 & 4 & $\mathrm{~N} / \mathrm{A}$ & 34 & 6 & $\mathrm{~N} / \mathrm{A}$ & 12 & 2 & N/A & 11 & 2 & N/A \\
\hline \multicolumn{23}{|l|}{ Age-group } \\
\hline$<25$ years of age & 249 & 36 & 14 & & 16 & 6 & & 5 & 2 & & 9 & 4 & & 17 & 7 & & 4 & 2 & & 3 & 1 & \\
\hline $25-28$ years & 169 & 39 & 23 & & 22 & 13 & & 7 & 4 & & 10 & 6 & & 9 & 5 & & 5 & 3 & & 5 & 3 & \\
\hline$>=29$ years & 184 & 15 & 8 & $<0.001^{*}$ & 5 & 3 & $0.001^{*}$ & 4 & 2 & 0.366 & 7 & 4 & 0.482 & 8 & 4 & 0.531 & 3 & 2 & 0.571 & 3 & 2 & 0.410 \\
\hline \multicolumn{23}{|l|}{ Gender } \\
\hline Female & 389 & 63 & 16 & & 31 & 8 & & 12 & 3 & & 17 & 4 & & 24 & 6 & & 5 & 1 & & 5 & 1 & \\
\hline Male & 213 & 27 & 13 & 0.247 & 12 & 6 & 0.287 & 4 & 2 & 0.379 & 9 & 4 & 0.933 & 10 & 5 & 0.454 & 7 & 3 & 0.093 & 6 & 3 & 0.180 \\
\hline \multicolumn{23}{|l|}{ Major travel flu zone } \\
\hline Southeast Asia & 252 & 39 & 15 & & 16 & 6 & & 3 & 1 & & 11 & 4 & & 17 & 7 & & 5 & 2 & & 5 & 2 & \\
\hline Central \& South America & 222 & 36 & 16 & & 20 & 9 & & 10 & 5 & & 9 & 4 & & 10 & 5 & & 5 & 2 & & 5 & 2 & \\
\hline Asia, other & 21 & 2 & 10 & & 1 & 5 & & 0 & 0 & & 0 & 0 & & 0 & 0 & & 1 & 5 & & 0 & 0 & \\
\hline Africa & 107 & 13 & 12 & 0.687 & 6 & 6 & 0.580 & 3 & 3 & 0.132 & 6 & 6 & 0.702 & 7 & 7 & 0.469 & 1 & 1 & 0.679 & 1 & 1 & 0.771 \\
\hline
\end{tabular}

Age was summarized into tertiles: $<25$ years, $25-28$ years and $>=29$ years. N/A Not Applicable

a In 10 individuals where the pre-travel titre was $\geq 40$ there was evidence of re-infection (4 fold rise in antibody titre)

$P$ value throughout is Pearson's chi-squared; Significance assigned (*) at $p<0.01$ 
Brisbane. Of those who departed before the 'public health emergency of international concern' (pandemic) was formally declared on 25 April 2009 [11] $(n=107)$, $22 \%$ were already positive for $\mathrm{A}(\mathrm{H} 1 \mathrm{~N} 1 \mathrm{pdm} 09)$ as early as January 2009. There was no difference in age or gender compared to those who were H1N1pdm09 negative pre-travel.

\section{Influenza symptoms and infections}

Of all 602 travelers, 209 (35\%) had fever while traveling with a median temperature of $38.5{ }^{\circ} \mathrm{C}$ (range 38.0 to 41.4 $\left.{ }^{\circ} \mathrm{C}\right)$. Five percent $(n=32 / 602)$ met the definition for ILI of whom seven complained of 2 ILI episodes. A further $n=149$ with fever also complained of headache, retrosternal pain or myalgia but did not meet the ILI definition. Of ILI episodes $(n=39), 54 \%$ were accompanied by myalgia, $26 \%$ by joint pain, $36 \%$ by diarrhea and $21 \%$ by vomiting. A doctor's visit due to ILI was reported in $44 \%(14 / 32)$ of cases. Diagnostic confirmation of the cause was not available. The incidence of first episode of ILI was 0.24 per 100 person-weeks of travel ( 95 $\%$ CI: $0.17-0.34$ ) and of fever $>38^{\circ} \mathrm{C}, 1.6$ per 100 personweeks (95\% CI:1.4-1.8), similar in early weeks of travel (i.e. the first 12 weeks) and late travel periods. Any influenza virus infection was serologically confirmed in 38 of the 209 travelers with fever $\left(\mathrm{PPV}_{\text {fever }}=18 \%\right)$ and 12 of 32 travelers with ILI $\left(\mathrm{PPV}_{\mathrm{ILI}}=38 \%\right)$.

Overall, 90 travelers seroconverted (attack rate $=15 \%$ ): $n=53(9 \%)$ seroconverted for 1 virus only (half were H1N1pdm09); 26 (4\%) for 2 viruses (16 were for both H3N2 viruses, two related strains where cross-reactivity was expected); 7 for 3 viruses and 4 people for 4 viruses. The only factor associated with any seroconversion was age (Table 1), and per-virus, only in those who seroconverted for H1N1pdm where more seroconversions occurred in those aged 25-28 years (Table 1). Influenza transmission zone visited was not a significant factor in seroconversion (Table 1). The AR for symptomatic infection (fever and ILI) was $6.3 \%(38 / 602)$ and $2 \%(12 / 602)$, respectively. Travelers that seroconverted, particularly to H1N1pdm09, were more likely to complain of ILI. (OR ref:H1N1pdm09 6.2 [95 \% CI:2.6-14.4], Table 2). Seroconversion to an increasing number of viruses was positively

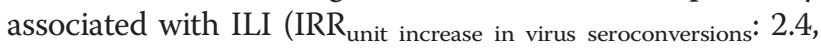
$95 \%$ CI:1.5-4.0, $p=0.001$ ). No seasonality (data not shown) or differences across influenza transmission zones (Fig. 1) was found with ILI onset or fever $>38^{\circ}$.

\section{Discussion}

In this young cohort of long-term travelers to (sub) tropical countries (2009 to 2012), the attack rate for confirmed influenza virus infection was $15 \%$. This is higher than the 1-7 \% found in other, mainly short-term traveler studies $[1,12,13]$ and closely mirrors seasonal rates
Table 2 Association between individual virus seroconversion and influenza like illness (ILI) during the study period (2009 to 2012)

\begin{tabular}{llll}
\hline Virus & Odds ratio $^{\text {a }}$ & $95 \% \mathrm{Cl}$ & $p$ value \\
\hline A/California/007/09 H1 N1 pdm & 6,2 & $2.6-14.4$ & 0.000 \\
A/Brisbane/59/07 & 1,2 & $0.2-9.3$ & 0.866 \\
A/Brisbane/10/07 & 3,6 & $1.1-11.0$ & 0.028 \\
A/Perth/16/09 & 1,8 & $0.5-6.2$ & 0.354 \\
B/Florida/4/06 & 1.0 & {$[---]$} & {$[---]$} \\
B/Brisbane/60/08 & 1.0 & {$[---]$} & {$[---]$} \\
\hline
\end{tabular}

${ }^{a}$ Odds ratio of association between seroconversion with individual virus and complaining of ILI. Univariable logistic regression by virus

of infection in the (unvaccinated) general population in temperate [14] and tropical [15] regions during the same period, reflecting the prolonged travel duration. For symptomatic infection, we found attack rates of $6.3 \%$ (fever alone) and $2 \%$ (ILI), respectively, which was higher than in two short-term studies that found attack rates of $0.9-1.3 \%$ for confirmed infections with fever alone $[1,12]$ and $0.8 \%$ for ILI [12]. The results of symptomatic infections however, should be interpreted with care. First, some studies use different definitions than ILI for symptomatic infections and do not report fever as the only symptom of confirmed infection [13]. Second, fever is a very common symptom in travelers [1, 12]. At the same time, confirmed infections without fever were found in 32 and $83 \%$, respectively $[1,12]$. Because virological data from nasopharyngeal sampling was not available for any of the studies, we can not be sure whether the symptoms were caused by influenza or by other infections. In our study, both the proportion of travelers with fever $(35 \%)$ and the proportion of travelers with confirmed infections without fever (58 \%) were high. Therefore we did not calculate IR's for symptomatic influenza infections.

As shown elsewhere [15], travelers in their mid-20s were more susceptible to $\mathrm{A}(\mathrm{H} 1 \mathrm{~N} 1 \mathrm{pdm} 09)$ infection than other viruses. The majority of respondents were immune to at least one virus pre-travel, and 1/5th departing before the pandemic was declared were positive for $\mathrm{A}(\mathrm{H} 1 \mathrm{~N} 1 \mathrm{pdm} 09)$ as early as January 2009 . Forty percent of travelers were infected with $>1$ virus while traveling and 10 people experienced a reinfection. Travelers infected with $\mathrm{A}(\mathrm{H} 1 \mathrm{~N} 1 \mathrm{pdm} 09)$ during travel were more likely to be symptomatic with ILI. Overall, the positive predictive value of ILI was $38 \%$. We found no evidence of seasonality or destination-specific risk, and travel was not a risk factor for severe disease.

There were some limitations to our study. The pretravel influenza vaccination status was not confirmed. However, in the Dutch healthcare system, it is very uncommon that healthy, young travelers are vaccinated. 
Another possible limitation is that travelers only measured their temperature if they 'felt feverish' rather than daily. This may have lead to an underestimate of the proportion of travelers with fever, and an overestimate of the number of asymptomatic infections.

Vaccination for travelers against influenza has been discussed [16]. In the USA, influenza vaccination is recommended for all US residents aged $\geq 6$ months [17]. The USA guidelines for international travel (Yellow Book, 2016) say 'any traveler who wants to reduce the risk for influenza infection should consider influenza vaccination $\geq 2$ weeks before departure if they plan to travel to the tropics'. According to WHO, influenza vaccination should be part of the routine immunization program for international travelers belonging to a risk group, in particular during influenza seasons [18].

In the Netherlands, only people at risk for complications are adviced influenza vaccination. Because there is no evidence that travel is an additional risk factor for influenza, the Dutch guidelines for travelers health advice do not recommend influenza vaccination for travelers other than those at high risk of complications.

\section{Conclusions}

We found that the attack rate of influenza in long-term travelers closely mirrors seasonal rates in the general population in temperate and tropical regions and travel was not a risk factor for severe disease. Influenza vaccination pre-travel is therefore most important for people at risk of medical complications due to influenza.

\section{Ethical approval and consent to participate}

The study was approved by the Medical Ethics Committee of the Academic Medical Center.

Pre-travel, written informed consent was obtained form all participants.

\section{Consent for publication \\ Not applicable.}

\section{Availability of data and materials}

Data will be shared upon request. Identifying/confidential patient data however will not be shared.

\footnotetext{
Abbreviations

AR: attack rate; HI: hemagglutination-inhibition; ILI: influenza like illness; PPV: positive predictive value.
}

\section{Competing interests}

Since this research was completed, Dr. Whelan has left the Public Health Service and was working in Research and Development at Novartis Vaccines, Amsterdam, The Netherlands (now a GSK company). Novartis Vaccines in no way contributed to the funding of this study, nor had any input whatsoever into the manuscript. The other authors do not have any conflicts of interest to declare.

\section{Authors' contributions}

GR, AH and GS conceived and designed the study, interpreted the analysis and contributed to writing the manuscript. SB conducted the study, collected the data and contributed to data management analysis and interpretation. JW managed the data, conducted the analysis and wrote the manuscript. All authors have read and approved the final version of the manuscript.

\section{Acknowledgements}

We thank the medical doctors and nurses of the Public Health Service Amsterdam for their assistance in participant inclusion and data collection, particularly Joan Kint for her extensive work in this study and Ruud van Beek for excellent technical assistance and Floor Elfrink for her producing the figure and critical advice and review of the paper.

\section{Funding}

This study was conducted within the Amsterdam Academic Collaborative Center on Public Health: a collaboration between the Public Health Service of Amsterdam and the Academic Medical Center of the University of Amsterdam, the Netherlands. The Amsterdam Academic Collaborative Center on Public Health is financially supported by the Netherlands Organization for Health Research and Development (ZonMw; grant number 7115 0001).

\section{Author details}

${ }^{1}$ Department of Infectious Diseases, Public Health Service Amsterdam, Nieuwe Achtergracht 100, 1018WT Amsterdam, The Netherlands. ${ }^{2}$ Academic Medical Centre, Amsterdam, The Netherlands. ${ }^{3}$ Erasmus Medical Center, Rotterdam, The Netherlands. ${ }^{4}$ National Coordination Centre for Traveler's Health Advice, Amsterdam, The Netherlands.

Received: 25 May 2015 Accepted: 9 April 2016

Published online: 16 April 2016

\section{References}

1. Mutsch M, Tavernini M, Marx A, et al. Influenza virus infection in travelers to tropical and subtropical countries. Clin Infect Dis Off Publication Infect Dis Soc Am. 2005;40(9):1282-7.

2. Odolini S, Parola P, Gkrania-Klotsas E, Caumes E, Schlagenhauf P, LopezVelez R, et al. Travel-related imported infections in europe, EuroTravNet 2009. Clinical microbiology and infection: the official publication of the european society of clinical microbiology and infectious diseases. Clin Microbiol Infect. 2012;18(5):468-74.

3. Reid D, Dewar RD, Fallon RJ, Cossar JH, Grist NR. Infection and travel: the experience of package tourists and other travellers. J Infect. 1980;2(4):365-70.

4. El Bashir H, Haworth E, Zambon M, Shafi S, Zuckerman J, Booy R. Influenza among U.K.pilgrims to hajj, 2003. Emerg Infect Dis. 2004;10(10):1882-3.5.

5. Miller JM, Tam TW, Maloney S, et al. Cruise ships: high-risk passengers and the global spread of new influenza viruses. Clin Infect Dis Off Publication Infect Dis Soc Am. 2000;31(2):433-8.

6. Davis XM, Hay KA, Plier DA, et al. International travelers as sentinels for sustained influenza transmission during the 2009 influenza A(H1N1)pdm09 pandemic. J Travel Med. 2013;20(3):177-84.

7. Palmer D, Dowdle W, Coleman M, Schild G. Hemagglutination in hibition test. Advance laboratory techniques for influenza diagnosis. Procedural guide. Atlanta: US Department of Health, Education, and Welfare; 1975. p. 25-62.

8. Masurel N, Ophof P, de Jong P. Antibody response to immunization with influenza A/USSR/77 (H1N1) virus in young individuals primed or unprimed for A/New Jersey/76 (H1N1) virus. J Hyg (Lond). 1981;87(2):201-9.

9. World Health Organisation. WHO recommendations on the composition of influenza virus vaccines. (Ed.^(Eds). http://www.who.int/influenza/vaccines/ virus/recommendations/en/. Accessed 14 Apr 2016.

10. World Health Organisation. Influenza Transmission Zones. (WHO, 2011). http://www.who.int/csr/disease/swineflu/Influenza_Transmission_Zones.pdf. Accessed 14 Apr 2016.

11. Novel Swine Origin Influenza A(H1N1) Virus Investigation Team, Dawood FS, Jain $\mathrm{S}$, et al. Emergence of a novel swine-origin influenza A (H1N1) virus in humans. N Engl J Med. 2009;360(25):2605-15.

12. Belderok SM, Rimmelzwaan GF, van den Hoek A, Sonder GJ. Effect of travel on influenza epidemiology. Emerg Infect Dis. 2013;19(6):925-31. 
13. Ratnam I, Black J, Leder $\mathrm{K}$, et al. Incidence and risk factors for acute respiratory illnesses and influenza virus infections in Australian travellers to Asia. J Clin Virol. 2013;57(1):54-8.

14. Hayward AC, Fragaszy EB, Bermingham A, et al. Comparative community burden and severity of seasonal and pandemic influenza: results of the Flu Watch cohort study. Lancet Respir Med. 2014;2(6):445-54.

15. Horby P, le Mai Q, Fox A, et al. The epidemiology of interpandemic and pandemic influenza in Vietnam, 2007-2010: the Ha Nam household cohort study I. Am J Epidemiol. 2012;175(10):1062-74.

16. Freedman DO, Leder K. Influenza: changing approaches to prevention and treatment in travelers. J Travel Med. 2005;12:36-44.

17. Prevention and Control of Influenza with Vaccines. Recommendations of the advisory committee on immunization practices (ACIP) — United States, 2012-13 influenza season. MMWR. 2012;61 (32):613-8. http://www.cdc.gov/ mmwr/preview/mmwrhtml/mm6132a3.htm. Accessed 14 Apr 2016.

18. Weekly epidemiological record, No. 47, 23 November 2012. Vaccines against influenza WHO position paper -November 2012. http://www.who.int/wer/ 2012/wer8747.pdf?ua=1. Accessed 14 Apr 2016.

Submit your next manuscript to BioMed Central and we will help you at every step:

- We accept pre-submission inquiries

- Our selector tool helps you to find the most relevant journal

- We provide round the clock customer support

- Convenient online submission

- Thorough peer review

- Inclusion in PubMed and all major indexing services

- Maximum visibility for your research

Submit your manuscript at www.biomedcentral.com/submit
Biomed Central 